\title{
Astronomy education and scientific schools in Ukraine
}

\author{
Yaroslav S. Yatskiv and Iryna B. Vavilova \\ Main Astronomical Observatory of the NAS of Ukraine, \\ Akad. Zabolotnogo St., 27, Kyiv MSP 03680, Ukraine \\ email: yatskiv@mao.kiev.ua irivav@mao.kiev.ua
}

\begin{abstract}
We describe briefly the current state of astronomical education in Ukraine, namely the secondary, higher, and post-graduating education systems. A special attention is paid to so called "scientific schools", non-formal groups of scientists formed by recognised astronomers, which have played and continue to play an important rôle in development of the astronomy education system. Among the founders of scientific schools were the well-known professors Alexander Ya. Orlov (Odessa University), Nikolai P. Barabashov (Kharkiv University), Sergei K. Vsekhsvyatsky (Kyiv University), Semen Ya. Braude (Kharkiv Polytechnical Institute), and Vladimir P. Tsesevich (Odessa University). We also give a general review on the history of astronomy education during the 16th-18th centuries. In 2000 astronomy was reinstated into the current 12-year secondary education curriculum of Ukraine. At present, some elements of astronomical knowledge are included in the lessons of "Natural Sciences" for pupils in the 5th - 10th grades. Astronomy is included as a basic course both in general (non-specialised) schools (17 academic hours in the last 11th or 12th grade) and in lyceums of the natural sciences (34 academic hours in the 12th grade). It is included also as an optional course in the educational program of gymnasiums in humanities. Every year about 75 young persons enter the Ukrainian universities to become astronomers. Results of our monitoring of the efficiency of astronomical higher educational system indicate that about $80 \%$ of the entered university students finish their education in 5 years; $50 \%$ of those who finished the cursus were working in astronomy. Since 1992 more then 100 astronomers defend Theses of Cand. Sci. (similar to Ph.D) and about 40 astronomers defend Theses of Dr. Sci. (topmost scientific degree, similar to Dr. Hab.). One of our presentday problems is a brain drain of young scientists. About 50\% of those who obtained Cand. Sci. degree work outside Ukraine. At the same time in Ukraine we have a lack of experienced persons to work in astronomical instrumentation and observations.
\end{abstract}

Keywords. Astronomy education, history, A.Ya. Orlov, N.P. Barabashov, S.K. Vsekhsvyatsky

\section{Brief history of the development of astronomical education system}

Astronomy has a long-standing tradition in Ukraine. The ancient archaeological finds with possible astronomical symbols and calendars revealed on the area of recent Ukraine are dated to the period of 15th millennium BCE to the 7th century (see the contribution by Vavilova \& Artemenko in this volume, page 821). The first astronomical observations and their writing records are dated to the times of Kievan Rus (10-13 centuries). For example, the authors of the Lavrentievsky chronicle described the solar eclipses of 1064, 1091, 1115, and 1230 and the lunar eclipses of 1161 as well as comet Halley in 1066. In 1483 the first printed book on astronomy was written by physician and astronomer Georgii Drohobich, who was a well-known author of Ukrainian origin (Isaievych 1994).

Systematic learning in astronomy is connected with an activity of the first Ukrainian universities in the 16-18th centuries, namely the Ostroh Slavic, Greek and Latin Academy 
(the first higher educational establishment of the Eastern Slavic nations, 1576), the KyivMohyla Academy (the first stage of its development was in 1615-1817; reestablished in 1992), and L'viv University (1661).

Among the interesting facts of the history of these institutions are the following. On 5 May 1581 in Ostroh, the first poetic and religion calendar 'Short Description of the Deeds of Old Times', known as Chronology by Andrii Rymsha, scientist of Belorussian origin, was published. Rymsha had lectured in mathematics and astronomy at the Ostroh academy. Another outstanding astronomer and mathematician Jan Latosius, scientist of Polish origin, published 'Prognostic' (1595), notes on solar eclipse of 1598 and comet's motion of 1596. There are evidences that the first telescopic observations at the Ostroh Academy were conducted in 1620 s.

Ivan Kopievsky, a graduate of the Kyiv-Mohyla Academy, issued the first stellar map in the Slavic language in Amsterdam in 1699 and the basics of naval astronomy in 1701. The prominent Ukrainian-Russian philosopher, scientist and religious figure, Pheophan Prokopovich, who worked at the Kyiv-Mohyla Academy in 1705-1716 (rector in 1711-1716), gave astronomical lectures based on theories of Copernicus and Galileo. Propopovich developed the philosophical foundation of the law of matter and motion unity, which later on was generalised by Mikhail Lomonosov. The first astronomical cabinet at the Kyiv-Mohyla Academy was established by Irinei Fal'kovsky, outstanding Ukrainian scientist and religious figure of 1780s. He equipped this cabinet with telescope, astrolabe, Copernicus spheres, celestial and geographical globes etc. Fal'kovsky lectured on mathematics and astronomy, and among the topics were the Kepler's theory of motion of planets, comets, visible motions of Sun and Moon, stars etc. In 1813-1823 Fal'kovsky established a small observatory at the territory of Mikhailovsky Cloister in Kyiv. His books 'Abridgements of the Mixed Mathematics' and 'Misyatseslovy' (two books with the detailed calendars of astronomical events and observations in 1799 and 1800) are of a special interest.

Among the renewed scientists of the Astronomical Observatory of L'viv University (founded in 1771) were S. Serakowski, the first director of the observatory, and Lysogorski, who conducted astronomical observations with a Newtonian telescope; T. Sekezhynski, professor of mathematics; J. Lesganig, a former prefect of the Vienna Observatory, and others. The astronomical career of the outstanding Hungarian astronomer F. H. von Zach began at L'viv observatory in 1776 as professor of mathematics. Later on he established an observatory at the Seeberg hill (Gotha, Germany), founded one of the first regular astronomical journals Monatliche Corespodenz as well as initiated the first international astronomical meeting (see for a detailed history of L'viv Astronomical Observatory Novosaydly 2007).

In 1821 the Naval Observatory was established in Mykolaiv, which functioned in 19121991 as a department of the Pulkovo Observatory (St. Petersburg, Russia). Later on the classical university observatories were founded in Kyiv (1845), Odessa (1871), and Kharkiv (1883). Being mostly engaged in education, these observatories also conducted research in astronomy. During the 20th century, the professors of these universities Alexander Ya. Orlov, Nikolai P. Barabashov, Sergei K. Vsekhsvyatsky, and Vladimir P. Tsesevich, recognised Ukrainian lecturers and scientists, have played a crucial rôle in the formation of astronomical education and of the research system in the USSR and Ukraine.

A new impetus for development of the astronomical research in Ukraine was connected with foundation of the astronomical institutions of the Russian Academy of Sciences (in 1917-1991 the USSR Academy of Sciences) and the Ukrainian Academy of Science (later on the Academy of Science of the UkrSSR, since 1992 the National Academy of Sciences of 
Ukraine). Among them are the Southern department of the Pulkovo observatory in Simeiz (Crimea, 1909), which now belongs to the Crimean Astrophysical Observatory of the Ministry for Education and Sciences of Ukraine; the Gravimetric Observatory in Poltava (1926), which is now a division of the Institute of Geophysics; the Main Astronomical Observatory in Kyiv (1944); the Crimean Astrophysical Observatory in the Naukove village (1945); the Radio Astronomical Observatory of the Institute of Radio Physics and Electronics in Grakovo (1958), which later on became a division of the Institute of Radio Astronomy in Kharkiv (1985); the High-Altitude Observatory at the Peak Terskol, the North Caucasus (1970s), which later became a division of the International Center for Astronomical and Medical-Ecological Research (1992). Today the astronomy sector of the National Academy of Sciences of Ukraine is developed to less extent as compared to that at the universities (Yatskiv \& Vavilova 2003; Pavlenko et al. 2006).

\section{The system of astronomical education}

Ukraine is a highly-educated country, where more then $60 \%$ of citizens have a full secondary or higher education. In the age group of 18 years and older, about $30 \%$ of total population has some form of higher education (www.ukrcensus.gov.ua).

\subsection{Astronomical education in secondary schools}

During the Soviet time astronomy was a basic course in secondary schools of Ukraine (34 academic hours in the last 10th grade). From 1992 to 2000 astronomy was excluded from the secondary education basic curriculum due to unknown reasons. In 2000, as a result of persistent activity by the Ukrainian Astronomical Association (UAA) and with support of the Ministry for Education and Science of Ukraine, astronomy was reinstated into the current 12-year secondary education program. The present-day status of the astronomical education in secondary schools is as follows (see also Vavilova \& Yatskiv 2003; Pavlenko et al. 2006). Some elements of astronomical knowledge are included in the lessons of "Natural Science" for pupils in the 5th-10th grades. Astronomy lessons are included as a required course both in general (non-specialised) schools (17 academic hours in the last 11th or 12th grade) and in lyceums of the natural sciences (34 academic hours in the 12 th grade). Astronomy is included in educational program of gymnasiums of the humanities as an optional course.

This system of astronomical secondary education will certainly form the Weltanschauung of the new generation of Ukrainian citizens. For this aim several new textbooks and problem books as well as methodical books for school teachers written by I. Klimishin, I. Kryachko, M. Pryshlyak, A. Kazantsev and others were issued during the past few years (see http://astroosvita.kiev.ua/HTML/infot1.html). A lot of attention was paid also by governmental institutions to train experienced teachers in astronomy. Several of the Ukrainian universities are engaged in this activity, namely the Drahomanov National Pedagogical University of Kyiv, the State Pedagogical University of Mykolaiv, and the State Pedagogical University of Chernihiv.

\subsection{Astronomical education in high schools}

Higher astronomical education is popular in Ukraine. We list below the largest national universities, which have astronomy and space science related faculties and chairs: the Shevchenko National University of Kyiv (www.univ.kiev.ua), the V.N. Karazin National University of Kharkiv (www.univer.kharkov.ua), the I.I. Mechnikov National University of Odessa (www.onu.edu.ua), the Ivan Franko National University of L'viv (www.franko.lviv.ua), the National Technical University 'Kyiv Polytechnical Institute' 
(www.ntu-kpi.kiev.ua), the National University of Dnipropetrovsk (www.dsu.dp.ua), the V.I. Vernadsky Taurian National University in Simferopol (www.ccssu.crimea.ua/ tnu), the National University of Uzhgorod (www . univ. uzhgorod.ua), and the Zhukovsky National Aerospace University in Kharkiv (www.xai.edu.ua).

Every year about 75 young persons enter the Ukrainian universities to become astronomers. All astronomical chairs are structural divisions of the physical departments of universities. Therefore, our students-astronomers obtain a good training in physics and mathematics. During the 4th-5th grades they study the classical astronomical courses (astrometry, celestial mechanics, planetary physics, solar physics, general astrophysics, applied astrophysics, theoretical astrophysics, extragalactic astronomy etc.) as well as the special courses on contemporary astronomy (cosmology, space physics, high-energy astrophysics, radio astronomy, contemporary methods and instruments for observations, variable and double stars, etc.), and have seminars and training in observational astronomy. After the 4th year of training they obtain the Bachelor diploma in Physics. After graduating the university they obtain the Diplomas of Specialist or Master Science in Astrophysics/Astronomy.

Among the current problems of higher education we find the following. According to the Bologna process, astronomical courses are not included in the Bachelor program of physics from the first to third year of education. It has a negative effect on training students-astronomers. Besides several textbooks have to be renewed. Now such a renovation is ongoing. In 2008-2009 new textbooks were written: 'General Astronomy' by S.M. Andrievsky \& I.A. Klimishin, 'Theory of Relativity' by V.I. Zhdanov, 'General Astrometry' by D.P. Duma, and 'Fractal Geometry in Natural Sciences' by Yu.I. Gorobets, A.M. Kuchko and I.B. Vavilova.

Results of monitoring the efficiency of the astronomical higher educational system indicated that about $80 \%$ of the entered university students finished their education in 5 years; $50 \%$ of those who finished education were working in astronomy.

\subsection{Post-graduate studies}

As to a highest astronomical education in Ukraine we have to mention the post-graduate study. Divisions for the post-graduate studies are in the largest Ukrainian astronomical institutions (for details on the system of scientific degrees in Ukraine see Pavlenko et al. 2006). Every year about 10 astronomers defend Theses of Candidate Science (similar to Ph.D.) within $3-7$ years after they graduate from university and about 3 astronomers defend Theses of Doctor in Science (the topmost scientific degree in Ukraine, similar to Dr. Hab.). Since 1992 more then 100 astronomers defend Theses of Cand. Sci. and about 40 astronomers defend Theses of Dr. Sci. in specialties related to astronomy and astrophysics. One of our present-day problems is a brain drain of young scientists. About $50 \%$ of those who obtained a Cand. Sci. degree work outside Ukraine. At the same time in Ukraine we have a lack of experienced persons to work in astronomical instrumentation and observations.

\subsection{Support of astronomical education}

In Ukraine there are various governmental and non-governmental systems of support for education and scientific research of students and young scientists, including astronomers. The President of Ukraine, the Verkhovna Rada (Parliament), Government, National Academy of Sciences and other state bodies established special prizes and grants for young scientists. For advertising astronomy in secondary and higher education there are several non-governmental institutions in Ukraine, among them the so-called 'Mala Akademiya Nauk' (www.man.gov.ua), the Victor Pinchuk Fondation 
'Zavtra.ua' (pinchukfund.org/ru/projects/edu/zavtraua), and the Ukrainian Astronomical Association (www.ukrastro.com.ua) which provide support for young talented astronomers.

\section{Recognised astronomical leaders of Ukraine and their scientific schools}

As we mentioned above during the 20th century in Ukraine several recognised astronomical centers were established thanks to the activity of professors A.Ya. Orlov, N.P. Barabashov, S.K. Vsekhsvyatsky (see Andrienko \& Zosimovich (2005)), S.Ya. Braude (see Vavilova et al. (2007) and Konovalenko (2000)), and V.P. Tsesevich (see Karetnikov (1996) and Andronov (2003)). Hereafter for understanding the rôle of scientific schools for developing astronomical education we briefly describe the life and scientific heritage of A.Ya. Orlov, N.P. Barabashov, and S.K. Vsekhsvyatsky.

\subsection{Alexander Ya. Orlov}

Alexander Yakovlevich Orlov (Orloff) or Olexander Yakovych Orlov (in Ukrainian) was born in Smolensk (Russia), in the family of a poor priest having 13 children. By this reason, Alexander's distant kinswoman Mrs. K. Vitte took care of his upbringing and education. In 1898 A. Orlov left a gymnasium in Voronezh (Russia) and entered the physical-mathematical faculty of the St.-Petersburg University. After successfully graduating from the university he went abroad to prepare for professorship (with a partial support of K. Vitte). Orlov studied astronomy and mathematics in Paris, celestial mechanics in Lund, and seismology in Gottingen. After he came back to Russia he worked at the Astronomical Observatory of Yurev (now Tartu, Estonia) University (1905-1906) and the Pulkovo Observatory (1907-1908). His scientific interest was in the study of the Earth as a complex dynamic system that responds both to external and internal actions. He understood that observed latitude variations and tidal deformations of the Earth offer a means for determining general mechanical properties of our planet and testing its internal structure models. On the basis of tidal observations conducted by him in Yurev, Alexander Orlov defended his Master Thesis in 1910 and become one of the leading experts in the study of terrestrial tides.

In 1912 he was appointed an extraordinary professor of the Novorossiysk (Odessa) University (ordinary professor from 1915) and director of the Astronomical Observatory. From this time up to his death in 1954 Orlov's life and scientific activity were connected with Ukraine. In this period Orlov produced works which played a significant rôle in the formation of a new view on geodynamical research. These works were noted for original treatment of astronomical, seismological and geophysical problems topical at that time. They stimulated new theoretical and experimental investigations including the establishment of new observatories in the Academy of Sciences of Ukraine (the Poltava Gravimetrical Observatory in 1926 and the Main Astronomical Observatory in Kyiv in 1944) as well as new stations for observations of latitude variations and terrestrial tides. Orlov was the first to propose new definitions of the terms 'mean latitude', 'mean pole of epoch' as well as to attach particular significance to investigations of the nature of the slow variations in latitude discovered by him.

The ideas proposed by A.Ya. Orlov were further elaborated by his students from Novorossiysk University and followers. Many of them became later the well-known scientists: N. Stoyko (France), I. Vitkovsky (Poland), Z. Aksenteva, N. Popov, and E. Fedorov (Ukraine), M. Bursha (Chesh Republic), I. Dyukov (Russia). These personalities had own 
scientific followers, who made valuable contributions to the development of astronomy and geodynamics in the world (Yatskiv et al. 2005).

For his outstanding scientific results Alexander Ya. Orlov was elected as a Member of Academy of Sciences of Ukraine (1919-1922, and after 1939) and Corresponding member of the Academy of Sciences of the USSR (1927).

\subsection{Nikolai P. Barabashov}

Nicolai Pavlovich Barabashov (Mykola Pavlovych Barabashov in Ukrainian) -the renowned Ukrainian astronomer in the physics of the Moon and planets, member of the Academy of Sciences of Ukraine (since 1948)- was born on March 29, 1894 in Kharkiv in the family of a professor of medicine. After graduating from Kharkiv University in 1919 he was offered to stay at the department of astronomy with a professorship. From 1930 until his death on June 29, 1971, Barabashov was a director of the Astronomical Observatory of the Kharkiv University (professor of astronomy since 1934 and a rector of the university in 1943-1946). The main results of Barabashov's research are the following.

In 1918 Barabashov showed that the surface of Moon was composed of volcanic rocks of basaltic type with a large porosity. This conclusion was confirmed when the Soviet space lunar missions were carried out in 1959-1964. He was one of authors and the editor of the first 'Atlas of the far side of Moon', where the lunar images taken by the automatic space station 'Luna-3' (1960) were displayed. He conducted several pioneering research of Mars. First of all, results of a large series of observations in 1920-1926 with use of the 270-mm reflector and color-filters allowed him to construct the surface map of Mars. After developing methods of photographical photometry for studying the planets and the Moon, Barabashov conducted in the 1930s a photographic photometry study of Mars and Venus in different frequency ranges. It allowed him to determine the optical parameters (reflectance, color of different details, reflection law) of the surface of Mars as well as the quasi-reflection character of light from the visible surface of Venus (1932). For the first time in the USSR, a spectrohelioscope was constructed, with N. Ponomarev, which was used in the Soviet Service of Sun. For many years Barabashov was a chair of the Planetary Commission of Astronomical Council of the Academy of Sciences of the USSR and he played a crucial rôle in the planning the astronomical and space related research at the beginning of space era.

Barabashov' pedagogical and scientific work resulted in the formation of a large collective of scientists involved in study of Solar System bodies, so-called the 'Kharkiv planetological school'. The main areas of research, which characterise this school are photographic photometry, spectrophotometry, surface colorimetry of planets and Moon; solar physics; astronomical instrument-making, and solar physics. Now among the recognised scientists who represent this school in Kharkiv are Yu. G. Shkuratov (research of the Moon), D.F. Lupishko (research of asteroids), L.A. Akimov (solar physics), V.N. Dudinov (gravitational lensing). It is important to note that in 1967 one of Barabashov's post-graduate students, I.K. Koval, founded the department of planetary physics at the Main Astronomical Observatory in Kyiv (now Koval is a professor of the State University of Chernihiv). Thanks to Koval's work the Barabashov's planetological school of scientists extended its activity to Kyiv. Here the well-known experts O. Morozhenko, E. Yanovitsky, A. Vidmachenko and others are working. Altogether a 'genealogical tree' of this scientific planetalogical school (Vavilova 2008) consists of more then 80 scientists (15 Dr. Sci. and about 70 Cand. Sci.). 


\subsection{Sergei K. Vsekhsvyatsky}

Sergei Konstantynovych Vsekhsvyatsky (June 20, 1905, Moscow - October 6, 1984, Kyiv) was the outstanding Ukrainian astronomer. After graduating from Moscow State University, he worked at the Shtenberg State Astronomical Institute in 1924-1935. In 1935-1939 he was collobarotor and deputy-director of Pulkovo observatory. In 1939-1981 he was professor and chair of the astronomical department of the physical faculty of the $\mathrm{T}$. Shevchenko National University of Kyiv.

His scientific fields of interest were in cometary physics and physics of Sun-Earth connections. In this field he formed his scientific school. Vsekhsvyatsky' recognised results and results obtained by his school are as follows.

Sun-Earth connections. In 1939 he discovered that the solar corona's matter is flowing constantly from the Sun to interplanetary space as well as there is rotation motion of corona as a whole; in 1953-1956 together with his post-graduate student, E. Ponomarev, he developed the two-component kinetic theory of the corpuscular flows from Sun (later on named the solar wind) and calculated its parameters and coronal ray forms. In 1956, the Thesis of Cand. Sci. was prepared by Ponomarev on this topic and sent to S.B. Pikelner as a opponent. Unfortunetely, for a long time this Thesis was detained by the opponent. Exactly at this time Parker's theory on the solar wind was published. By this reason the priority of Vsekhsvyatsky-Ponomarev discovery of the solar wind was very difficult to recognise taking into account that the solar wind discovery has been widely related to Parker. Vsehsvaystsky was one of the founders of the Soviet Service of Sun (1942). Among his scientific predictions that are not confirmed until now is the idea of synchronisation of the 11-years cycle of the solar activity with the motion of planets. He also initiated research on the polar Aurora and organised several expeditions to study this phenomenon.

Cometary physics. First of all, we would like to mention the fundamental monograph 'Physical characteristics of comets' (1958) by Vsekhsvyatsky (it has four editions prepared by Vsekhsvyatsky and his followers Andrienko and Karnenko). In this book the data on all the known comet appearances and their physical parameters are given. In 1920 s he discovered the gradual disintegration of the short-periodical comets that resulted from their young age. He supposed that there is inhomogeneity of the cometary atmosphere with nucleus-center distance (this effect was discovered in 1950 s by V. Konopleva). Vsekhsvyatsy dreamed to discover a new comet. It was done by his followers K. Churyumov and S. Gerasimenko. Now the Churyumov-Gerasimenko comet is a main target of the ESA mission 'Rosetta'. discovered by Vsekhsvyatsky' followers.

Among the most recognised predictions by Vsekhsvyatsky are the existence of rings around Jupiter, and volcanic activity at the satellites of planets, in particular, Jupiter, which was confirmed by the NASA missions 'Voyager'.

The first astronomical group of students superwised by Vsekhsvyatsky graduated from Kyiv University in 1948. During these 60 years of activities by the Vsekhsvyatsky scientific school many recognised works were published by by E. Pomamarev, K. Churyumov, D. Andrienko, V. Rubo, G. Milinevsky, V. Ivchenko, V. Konopleva, L. Shulman, P. Korsun, V. Zubko, A. Ivanova, and others.

\section{Conclusion}

In this paper we described a brief history of astronomical education in Ukraine with a special emphasizing on the period of 16-18th centuries. Basic information on the contemporary secondary, higher, and post-graduate education system in Ukraine is also 
provided. The modern educational and scientific system of Ukraine in field of astronomy and astrophysics has been established due to the extensive activity of several prominent astronomers, in particular, A.Ya. Orlov, N.P. Barabashov, S.K. Vsekhsvyatsky, S.Ya. Braude, and V.P. Tsesevich. As an example we described the scientific schools of three of them, namely Prof. A.Ya. Orlov in Odessa, Prof. N.P. Barabashov in Kharkiv, and Prof. S.K. Vsekhsvyatsky in Kyiv University. In near future we are planning to prepare a book on history of the astronomical scientific schools in Ukraine.

\section{References}

Andrienko, D. A. \& Zosimovich, I. D. 2005, in Sergei Vsekhsvyatsky (Kyiv: Kyiv University), p. 5 (in Ukrainian)

Andronov I. L. 2003, Odessa Astronomical Publications, 16, 5

Isaievych, I. 2004, in The Introduction of Arabic philosophy into Europe, C. E. Butterworth and B. A. Kessel (eds) (Leiden: Brill), p. 58

Karetnikov, V. G. 1996, Astronomical \&3 Astrophysical Transactions, 10, 21

Konovalenko, A. A. 2000, Geophysical monograph, 119, 311

Novosaydly, B. S. 2007, in Encyclopedia of L'viv, 1, A. Kozytsky \& I. Pidkova (eds) (L'viv: Litopys), p. 130

Pavlenko, Ya. V., Vavilova, I. B. \& Kostiuk, T. 2006, in Organizations and Strategies in Astronomy, Vol. 7, A. Heck (ed) (Berlin: Springer), p. 71

Vavilova, I. B. \& Yatskiv, Ya. S. 2003, Teaching of Astronomy in Asian- Pacific Region 19, 47

Vavilova, I. B., Konovalenko, A. A. \& Megn, A. V. 2007, Astron. Nachr., 328, 420

Vavilova, I. B. 2008, in 200 years of astronomy in the Kharkov University, Yu. G. Shkuratov (ed) (Kharkov: Kharkov National University), p. 166 (in Russian)

Yatskiv, Ya. S. \& Vavilova, I. B. 2003, Kinematics and Physics of Celestial Bodies 19, 569

Yatskiv, Ya. S., Korsun, A. A. \& Vavilova, I. B. 2005, Kinematics and Physics of Celestial Bodies 21,403 